\title{
Mujeres, cuerpos y trabajos en la narrativa de Marta Sanz
}

Somolinos Molina, Cristina

Universidad de Alcalá, España

cristina.somolinos@uah.es

Cita sugerida: Somolinos Molina, C.(2018).Mujeres, cuerpos y trabajos en la narrativa de Marta Sanz. En C. Somolinos Molina (ed.), "Escrituras del cuerpo: Marta Sanz". Olivar, 18 (27), e025. https://doi.org/10.24215/18524478e025

(c) (1) Esta obra está bajo licencia Creative Commons Atribución-NoComercial-CompartirIgual 4.0 Internacional (c) ${ }_{\mathrm{BY}} \mathrm{Na}_{\mathrm{SA}} \mathrm{http}: / /$ creativecommons.org/licenses/by-nc-sa/4.0/deed.es_AR 


\section{Mujeres, cuerpos y trabajos en la narrativa de Marta Sanz}

Women, bodies and works in the narrative of Marta Sanz

Cristina Somolinos Molina

Universidad de Alcalá, España

cristina.somolinos@uah.es

\section{Resumen:}

La escritura narrativa de Marta Sanz se presenta como vehículo de articulación de temas que tienen que ver con problemáticas de la subjetividad en las sociedades contemporáneas. De entre ellas, la representación de los trabajos desde la perspectiva de los cuerpos feminizados ocupa un lugar privilegiado. En este trabajo, trataremos de analizar las relaciones entre esta triple variable (mujerescuerpos-trabajos) en sus novelas Susana y los viejos (2006) y La lección de anatomía (2014 [2008]).

Palabras Clave: Marta Sanz, Novela, Género, Cuerpo, Trabajo.

\section{Abstract:}

Marta Sanz's novels deal with topics related to construction of subjectivity on contemporary societies. Representation of women's bodies on working contexts is an issue in which Sanz looks into in a critical way. In this work, our aim is to analyze the representation of a triple variable formed by women-bodies-labour in two novels: Susana y los viejos (2006) and La lección de anatomía (2014 [2008]).

KEYWORDS: Marta Sanz, Novel, Gender, Body, Labour.

\section{NARRATIVA ACTUAL Y TRABAJO FEMENINO: PROBLEMAS ${ }^{1}$}

Las manifestaciones literarias de los denominados "nuevos realismos", cuyo desarrollo se ha producido a partir de los años 90 del siglo XX en España, suponen un espacio idóneo para dar cabida a planteamientos que problematicen la realidad social desde diferentes ángulos. Autores como Belén Gopegui, Isaac Rosa, Rafael Chirbes, Elvira Navarro o Marta Sanz forman parte de este grupo de escritores críticos con la realidad social y con las inestabilidades del sistema tardocapitalista. De entre estas preocupaciones, destacan las formas de articular las representaciones literarias del trabajo y de los ambientes laborales, pues tal y como se ha puesto de manifiesto por parte de autores y autoras de esta corriente, constituyen problemas que han sido abordados de manera insuficiente en la narrativa española actual. Así lo han señalado varios autores y autoras, entre ellos Isaac Rosa (HOAC, 2013: s/n) o Marta Sanz (2007).

En un intento de incorporar algunas nociones de teoría marxista a la praxis de la crítica literaria y cultural, consideraremos como punto angular la noción de trabajo y los modos por los que el trabajo interviene en la construcción de la subjetividad. Dado que se hace hincapié en el trabajo en el mundo posfordista, MartínCabrera (2010: 118) señala que existe una necesidad de que los Estudios Culturales reincorporen a sus estudios una teoría cultural del trabajo, así como una teoría laboral de la cultura, todo ello teniendo en cuenta las relaciones de interseccionalidad que existen entre diferentes ejes de dominación (etnia, raza, clase, género). Desde este punto de vista, las relaciones de explotación se interrelacionan con otros conflictos que tienen que ver con la desigualdad de género, la lucha contra el racismo o con la sostenibilidad ecológica.

El concepto de interseccionalidad resulta clave para comprender las representaciones de las obras de Marta Sanz: los sujetos que construye se leen en función de las variables de género y de clase social. En este sentido, resulta de especial interés analizar cómo se articula en la actualidad la identidad de los sujetos a través del trabajo, y cómo el mundo del trabajo se convierte en ámbito donador de sentido. Plantear la noción de 
trabajo como cuestión central implica reconocer la importancia que tiene el ámbito de la producción en la cotidianidad y en la gestión del tiempo, así como en la construcción de diferentes proyectos de vida.

En el caso de las mujeres, el problema del trabajo adquiere unas dimensiones fundamentales en tanto que ha tenido un desarrollo histórico complejo. En el siglo XIX, en relación con el ascenso de la burguesía como clase, se impuso en España lo que Nash (1993: 614) ha denominado "discurso de la domesticidad", que establecía una rígida división de esferas sociales en la que los varones desarrollaban su actividad en el seno de la esfera pública, mientras que las mujeres lo hacían en la esfera privada. Todo ello se vio apoyado por una serie de discursos médicos, sociales y jurídicos que legitimaban la posición subalterna de la mujer y justificaban su dedicación a labores relacionadas con la reproducción y con los cuidados, amparados en una supuesta naturaleza de la mujer. Este discurso ha tenido un desarrollo complejo a lo largo del siglo XX, en tanto que se ha visto cuestionado desde los diversos planteamientos feministas y ha tenido continuidades en el discurso oficial franquista.

Desde diferentes puntos de vista, y a lo largo de la pasada centuria, el movimiento feminista ha ido problematizando estos discursos y planteando la construcción social del género. Siguiendo a Silvia Federici (2013: 25), negar el carácter naturalizado de la reproducción y del trabajo de cuidados supone aceptar que los atributos de la feminidad son, en realidad, funciones laborales. La reciente incorporación masiva de las mujeres al trabajo asalariado conllevó una modificación de la división tradicional de las esferas al incluir el acceso de las mujeres al ámbito público y fue interpretada en lo teórico como una oportunidad de emancipación y de liberación, así como de consecución de la igualdad, pero en la práctica supuso para las mujeres la obligación de hacer frente a una doble jornada laboral (Federici 1975a: 56).

Así pues, para plantear la cuestión del trabajo de las mujeres, conviene realizar una primera distinción entre trabajo y empleo, puesto que el énfasis que se ha puesto en el empleo o trabajo asalariado ha dificultado la visibilidad de otros trabajos que se realizan sin remuneración pero que, sin embargo, resultan fundamentales para la reproducción de la vida. Desde este punto de vista, consideraremos como trabajo todas aquellas actividades de producción y de reproducción que se desarrollan en el seno de una sociedad (Castillo et al. 2013: 7; Carrasco, 1991), teniendo en cuenta que se relacionan entre sí al satisfacer de algún modo las necesidades materiales e inmateriales de las personas. Solo si adoptamos esta perspectiva estaremos favoreciendo un punto de vista que incluya en su seno todos los trabajos realizados por las mujeres en la sociedad.

Partiremos de la idea de que la cuestión del trabajo femenino constituye un tema central en la obra de Marta Sanz, y de que sus formulaciones y discursos articulan una noción de trabajo desde una perspectiva integral que tenga en cuenta todas las actividades necesarias para que se asegure la continuidad de la vida en una sociedad. Para ello, se propone vertebrar el análisis en un eje triple y considerar las relaciones que existen entre las representaciones de los cuerpos, de los trabajos y el lenguaje empleado para llevarlas a cabo. A la hora de abordar el problema del trabajo femenino en la obra de Sanz, conviene acotar un corpus de obras en el que tratarlo. A pesar de que este tema también se trata en otras novelas de la autora - de entre ellas, especialmente Daniela Astor y la caja negra (2014) -, se han seleccionado dos de ellas que indagan en la cuestión de una manera directa. Se trata de Susana y los viejos (2006) y La lección de anatomía (2014 [2008]).

\section{El triángulo CUERPo-Trabajo-Lenguaje EN la obra de Marta SANZ}

El cuerpo en la obra de Marta Sanz constituye un espacio de reflexión constante, un lugar desde el que se vehicula una serie de relaciones entre los sujetos. Teniendo en cuenta la dimensión central del cuerpo en la obra de Sanz, resulta de especial relevancia establecer puntos en común entre las nociones de cuerpo, trabajo y lenguaje, ejes de nuestro análisis de la obra narrativa de la autora.

La articulación de texturas narrativas que se basan en la utilización de lenguajes simbólicos es una característica de los denominados “nuevos realismos" y constituye una constante en este tipo de literatura: el 
horno crematorio y el marjal para Rafael Chirbes en sus novelas Crematorio (Anagrama, 2008) y En la orilla (Anagrama, 2013), respectivamente, el cuarto oscuro en La habitación oscura (Seix Barral, 2013) de Isaac Rosa o la caja negra en el caso de Daniela Astor y la caja negra (Anagrama, 2013) de Marta Sanz son ejemplos de ello. En el caso de Marta Sanz, los símbolos van unidos a la construcción de los discursos históricos y culturales acerca del cuerpo en tanto que este ocupa una dimensión central en el devenir de la historia.

El interés de Sanz por el cuerpo, la urgencia de hablar del mismo y la necesidad de hacerla explícita es una constante en su obra, no solo narrativa, sino también poética y ensayística. Como ejemplo, se puede observar cómo esta inquietud se plasma en uno de sus poemas (Sanz, 2010: 10): "De la ciencia me interesa más/ el descubrimiento del endoscopio/ que todos los viajes a la luna./ ¿Me explico?/ Estoy hablando del cuerpo.”

La obra narrativa de Sanz da cuenta de una cotidianidad corporeizada y, por tanto, se centra en la manera como los individuos, en sus coordenadas sociales singulares, dan sentido a sus actuaciones diarias. El cuerpo ocupa una dimensión central en el interés de la escritura de Sanz, y se configura como lugar de la enunciación y como espacio de resistencia. En ello coincide con Adrienne Rich, quien en su afán de indagar en el papel del cuerpo en la sociedad patriarcal, proponía una caracterización del cuerpo como "la localización del terreno desde el que hablar con autoridad, como mujeres. No para trascender este cuerpo, sino para reclamarlo. Para volver a conectar nuestro pensamiento y nuestro lenguaje con el cuerpo de esta individua humana viviente concreta, una mujer" (1984: 207). De este modo, se vinculan dos cuestiones: el cuerpo y el lenguaje, en la medida en que necesitamos articular lingüísticamente el cuerpo como territorio en disputa, así como las relaciones con el cuerpo y lo que la lectura social de los cuerpos significa. Así lo expresa Lorena, personaje de Susana y los viejos: "no es el cuerpo lo que se desea, sino lo que el cuerpo significa" (2006: 129).

El potencial simbólico del cuerpo tiene que ver con las condiciones sociales en las que se inserta y los usos sociales a partir de los cuales adquiere diferentes significados. Esto lo convierte en un artefacto político en tanto que el cuerpo y los discursos en torno al cuerpo se plantean en su potencial subversivo: se trata, en las novelas de Marta Sanz, de dar cuenta de las contradicciones con respecto a los cuerpos que los discursos dominantes han articulado. El cuerpo, entonces, es para la autora el símbolo en el que se leen las estructuras sociales, culturales e históricas y al mismo tiempo es una ubicación, una posición desde la que se toma la palabra o desde la que no es posible hacerlo (González et al. 2014: 25).

De acuerdo con Adrienne Rich y sus reflexiones acerca de la política de la posición, no se puede desligar cualquier lucha por el sometimiento sin tener en cuenta la subordinación específica de las mujeres en función de su ubicación en un cuerpo femenino, de modo que "lo que el cuerpo significa" hace referencia a la serie de significados sociales del cuerpo que se asignan dependiendo de la posición que ocupa en las estructuras sociales. La posición que el cuerpo ocupa en la estructura confiere o niega unos privilegios. Quienes los poseen, son quienes se ocupan de nombrar, esto es, de articular simbólicamente unos significados que se imponen sobre los cuerpos dominados.

Estos privilegios se reflejan en las estructuras del lenguaje y en la ideología que contiene. De ese modo, por ejemplo, las diferencias de clase se articulan en Susana y los viejos en la siguiente reflexión de Maximiliano, acerca de Clara - personaje de clase trabajadora, trabajadora doméstica- y Pola — personaje de clase alta-, pues un mismo elemento de la realidad física se nombra de maneras diferentes:

Max recupera la imagen de la axila tensa de Pola, del sobaco estirado de Clara. Pola tiene senos y Clara tetas, Pola tiene vientre, Clara tripa, Pola tiene rostro, Clara, cara, Pola tiene cabello, Clara, pelo, Pola tiene pubis, Clara, potra, Pola tiene vagina, labios menores y mayores, una enorme complejidad de tejidos y fibras replegados, Clara tiene chocho, Pola tiene durezas, Clara, callos, Pola, cutículas, Clara, padrastros, Pola, marcas de expresión, Clara, arrugas, Pola, una boca fina, Clara, una boca de culo. Por eso, Max yace con Pola, Porque le dan miedo las asistentas y las torres de siete jorobados. Y, sin embargo, Max está convencido de que, de no ser por esos mínimos detalles, por fuera, Clara y Pola son la misma persona. (Sanz 2006: 79).

El pasaje evidencia cómo la manera por la que nombramos los cuerpos a través del código lingüístico plantea una articulación en términos de género y de clase como ejes de dominación. Desde el punto de vista de los dominados, revertir el uso del lenguaje a la hora de nombrar supone una herramienta para subvertir el 
orden establecido. De acuerdo con Sanz (2014b), "nombrar el cuerpo es conquistar el territorio", de manera que quienes nombran tienen la capacidad de determinar la posición que ocupan los nombrados.

En relación con esta preocupación por dar cuenta de los conflictos de clase a través de la escritura, la noción de trabajo en sentido amplio se coloca en un lugar preeminente, y se vehicula a través del tema del cuerpo, en tanto que el trabajo se realiza desde o con el cuerpo y los cuerpos se leen de distinta forma socialmente en función de si se consideran o no cuerpos productivos, de acuerdo con la ideología hegemónica.

El cuerpo, desde este punto de vista, se entiende como "superficie de inscripción de la subjetividad, como máquina productiva y deseante y, por tanto, simultáneamente como locus de la explotación y de la sujeción y punto de partida de la resistencia" (Laboratorio Feminista, 2006: 11). En el caso del trabajo femenino, además, hay que considerar la problemática específica que lleva asociada, teniendo en cuenta el énfasis que se ha puesto en el empleo o trabajo asalariado, que como señalábamos anteriormente ha dificultado la visibilidad de otros trabajos, no siempre remunerados, y asociados a los caracteres de una feminidad construida ideológicamente.

En la narrativa de Sanz, hay una problematización del trabajo, en general, y del trabajo que desarrollan las mujeres, en particular, en torno a tres ejes: en primer lugar, se plantea desde el punto de vista de la caracterización de los personajes -se trata de mujeres trabajadoras que suelen desempeñar trabajos ligados a la esfera de los cuidados o puestos que guardan relación con los atributos naturalizados de la feminidad-; en segundo lugar, a través del retrato de ambientes laborales, tanto en la esfera del trabajo asalariado (productivo) como de los cuidados (reproductivo), la maternidad se plantea como un trabajo; por último, por medio de mecanismos de autorreflexividad y de situación en relación con la política de la posición -a partir de la necesidad de resituarse críticamente en un lugar configurado a través del género y de la clase social.

Al mismo tiempo, el cuerpo es, para Marta Sanz, símbolo del lugar desde el que se producen los discursos. Escribir sobre el cuerpo es parte de la tarea de nombrar el territorio. En referencia a La lección de anatomía, la autora escribe lo siguiente:

El cuerpo vuelve a ser un elemento fundacional del autorretrato y escribir es ir tatuándose el cuerpo al mismo tiempo que descubrimos todo lo que ya tenemos escrito sobre la piel. La arruga, lo flácido, el pentimiento de la felicidad o las proximidades de la muerte. Nuestros deseos, nuestros trabajos. El retorno al punto de partida. Nombrar el cuerpo, conquistar el territorio: en eso consiste escribir (Sanz 2014b: 71).

Desde este punto de vista, si tenemos en cuenta que tomar la palabra es un acto político, la decisión de escribir, como manera de generar un discurso que tenga la capacidad de intervenir en el ámbito de lo público y de sumarse u oponerse a un universo de discursos, contradiciéndolos o mirando a la realidad desde otro lado, es una decisión política.

\section{El trabajo FEMENiNo en SUSANA Y LOS VIEJOS}

En el caso de Susana y los viejos, la intersección género/clase viene dada por la construcción de una tipología diversa de personajes femeninos que pone sobre la mesa los avatares de mujeres que ocupan diferentes posiciones en la escala social y que se enfrentan de maneras diversas a los atributos de la feminidad impuesta. De este modo, plantean modelos o bien continuistas o bien subversivos con respecto al paradigma de género dominante. Estos personajes tratan de analizar reflexivamente "los extremos de la realidad que los rodea, descubrir su lugar en el mundo, explicarse los porqués de sus turbaciones o elucidaciones de su degradación y angustias actuales" (Sánchez Dueñas 2012: 638).

El argumento de la novela muestra las diferencias entre tres generaciones de una familia: abuelos, padres e hijos. En el seno de la familia, encontramos a Felipe padre, viudo nonagenario, y a su difunta esposa, Micaela; Felipe hijo, arquitecto y empresario, y Lorena, su exesposa, heredera de una familia de terratenientes; Maximiliano (hijo de ambos) y su pareja, Pola, que llevan una vida bohemia y vacía, reflejo de la vacuidad del 
momento histórico; y las dos cuidadoras de Felipe padre: Clara, trabajadora del hogar, procedente del entorno rural, y Susana, geriatra del abuelo, y después esposa de Felipe y socia en la clínica de cuidados paliativos que ambos deciden construir. La trama tiene lugar en el acontecer cotidiano de la familia en un presente que entendemos que se sitúa en torno a los inicios del siglo XXI. Los narradores-personajes se sirven de una serie de analepsis que permiten entender cuáles son las relaciones de poder que se establecen dentro de la familia y en función de qué factores se plantean.

Como ha analizado Bonatto (2017: 10), Susana y los viejos supone la reescritura de dos tradiciones: por un lado, la tradición pictórica que hace referencia al relato bíblico de "Susana y los viejos" contenido en el Libro de Daniel en el Antiguo Testamento; por otro lado, la tradición literaria del realismo galdosiano, tomando como referencia la novela Fortunata y Jacinta. El discurso narrativo se vertebra en función de varios ejes que se encuentran estrechamente relacionados con el tema del relato bíblico: la tensión entre el amor, representado a través de diferentes tipos de relaciones que transgreden lo normativo, y la muerte, expresada a través de las referencias a la enfermedad y al dolor. A estos dos elementos, Sanz añade uno fundamental que aparece en primer plano a lo largo de toda la novela: la problematización del trabajo reproductivo o el trabajo de cuidados, que se convierte en elemento central porque pone de manifiesto cómo el trabajo de las mujeres sustenta y hace posibles las actividades productivas de la sociedad.

Los diferentes personajes femeninos encarnan distintos modos de enfrentarse a los roles de género tradicionales y rompen con la estrategia de la legitimación por la tradición: Susana, la geriatra que se ocupa de Felipe padre, representa el paradigma de mercantilización de los cuidados; Lorena, mujer de clase alta y madre de Maximiliano, plantea la emancipación de género en virtud de una ventaja de clase derivada de su posición social; Pola, pareja de Maximiliano, representa el paradigma de "nueva sumisión” en la generación de los nietos, dependiente económicamente de sus padres; Micaela, abuela de Maximiliano, encarna el ideal de la hija, esposa, madre y abuela sumisa y abnegada, en consonancia con el rol heredado de la ideología del franquismo para con las mujeres; Clara es la trabajadora doméstica que cuida, primero, a Felipe padre y, después, trabaja en casa de Felipe hijo. Además de estos personajes, que aparecen en la acción de una manera activa, se encuentran los testimonios de otras mujeres trabajadoras, tales como Rocío, trabajadora de origen ecuatoriano a quien contrata Felipe hijo, las trabajadoras domésticas con las que Clara coincide en el tren de Cercanías -Rosita, Fefa, Mirta y Angélica- o la portera del edificio donde vive Maximiliano, de la que sabemos que compatibiliza su trabajo de portera con el de asistenta doméstica en otros lugares.

Para analizar las representaciones del trabajo en Susana y los viejos, es necesario partir de la política de la posición a la que hemos aludido en el apartado anterior. Los personajes femeninos de la novela conforman un mosaico y todos ocupan una determinada posición en la estructura, que se puede establecer en función de la clase social. Uno de los elementos que sirven para medir esta posición es la dependencia del trabajo asalariado para la supervivencia. Desde este punto de vista, se pueden establecer dos grupos que los dividen entre quienes no necesitan el salario para salir adelante y quienes, por el contrario, dependen de él.

De entre los personajes que no dependen del salario porque ocupan una posición en la escala social en virtud de su ascendencia que les permite vivir holgadamente sin preocuparse del sustento, se encuentran Lorena y Pola. Lorena es hija de un terrateniente y ha recibido una herencia que le otorga un privilegio de clase con respecto a otras mujeres de la novela y esta ventaja la emplea para tratar de lograr su emancipación con respecto a los hombres. Pola es la pareja de Maximiliano y su situación de despreocupación con respecto al trabajo asalariado deriva de su dependencia económica con respecto a sus padres y al padre de Max, quienes le han asignado una cantidad de dinero mensual. En los dos casos, existe una relación con el trabajo asalariado que se utiliza con fines distintos.

El personaje de Lorena se nos presenta como el modelo de la mujer consumidora, hecha a sí misma, que no se mancha las manos con el trabajo, como expresa en sus reflexiones durante la clase de yoga:

No conseguiré estarme quieta y, sin embargo, nunca he producido manufacturas ni he cosido botones ni he tocado instrumentos musicales. Dejé de pintar. Entre mis manos, pollas erectas y productos acabados. Cosas ya hechas que se toman 
y consumen y utilizan para el propio gozo o para el propio beneficio [...] Sin pretender la gloria ni el olvido, a través de los trabajos. Yo soy mi trabajo. Yo soy mi producto. Yo soy mi soberbia. No soy una mujer manufacturera. No soy una artesana. No soy fuerza de trabajo. (Sanz 2006: 95).

Lorena es quizá el personaje femenino que goza de un grado más alto de emancipación otorgada por su ventaja comparativa de clase, pues renuncia al trabajo doméstico mediante la contratación de una trabajadora doméstica o delegando en Micaela estas tareas:

Ella dio todo un ejemplo de resistencia al negarse a atender al cupo de enfermos familiares que, por su condición femenina y a partir de los cuarenta años, le estaba adjudicado. [...] Mrs. Robinson había delegado en terceras personas esas obligaciones tácitas — normalmente había pagado por ello— ante las miradas de estupor de Micaela (Sanz 2006: 219).

La negación por parte de Lorena de llevar a cabo los trabajos domésticos tiene una serie de consecuencias -el hecho de que recaigan sobre Micaela o sobre otras mujeres más pobres- que ponen de manifiesto la necesidad social de buscar una solución de manera colectiva al reparto desigual de los trabajos domésticos.

En el caso de Pola, su relación de no dependencia del trabajo asalariado se deriva de su ascendencia. De este modo, Pola es una mujer de clase media-alta que se puede permitir vivir sin trabajar. Sin embargo, asume puntualmente empleos para buscar en el mundo del trabajo asalariado emociones que no encuentra en la aburrida cotidianidad de su vida acomodada:

Pola trabaja esporádicamente de cajera en una gran superficie comercial. Trabaja allí por las mismas razones por las que se viste de pobre y por las que come con frugalidad. Trabaja los días que la llaman para hacer suplencias por bajas médicas de otras cajeras ambulantes. (...) Pola no trabaja porque necesite dinero. Tanto su padre, como el de Maxi, les dan una asignación mensual, pero Pola ha decidido empaparse de vida, cortándose de vez en cuando las piernas contra los cajones del dinero de las cajas registradoras, empotrada en el pequeño espacio en el que las cajeras mueven los brazos al pasar los productos por el escáner (Sanz 2006: 64).

En el otro lado, se encuentran las mujeres que sí necesitan del trabajo asalariado para la supervivencia, y que se nos presentan como cuidadoras, tanto Micaela -quien no tiene trabajo asalariado y se dedica en exclusiva a las tareas del hogar- como Clara o Susana. En casa de los Amaro, el trabajo doméstico y de cuidados había recaído en la figura de Micaela, para quien los atributos de la feminidad son de una manera más clara funciones laborales (Federici, 2013: 25). Así lo recuerda Felipe cuando visita la casa de sus padres: "Al cerrar la puerta de entrada, Felipe cree oír la máquina de coser, el pedal, la aguja que atraviesa la tela; cree oír, e incluso oler, el crepitar del aceite en una sartén llena de patatas fritas” (Sanz, 2006: 101). A través de esta figura, Sanz presenta un modelo de mujer que tiene su raigambre en el "ángel del hogar" del discurso franquista sobre las mujeres y heredado del discurso de la domesticidad. Micaela renuncia a sus aspiraciones individuales para cuidar a los demás y, a costa de trabajar sin descanso por ello, crea la posibilidad de que los demás se desarrollen plenamente.

Susana se presenta como personaje ambiguo y enigmático por lo que tiene de transgresor de los códigos morales y de los tabúes de la sociedad en la que se inserta. Susana encarna el papel de la cuidadora que trata de hacer más llevadera la vida de los demás. Como se observa, tanto en el caso de Micaela como en el de Susana, el énfasis de su actividad vital se localiza en el bienestar y en la reproducción de la vida humana. La actuación de Susana obliga al lector a replantearse, al igual que hace Clara, los límites del cuidado: "el salto no es tan significativo: no existe tanta diferencia entre lavar las llagas de un anciano y acariciarle las mejillas o lamerle la cara interna de los muslos" (Sanz, 2006: 270). Asimismo, el hecho de que Susana decida embarcarse en la empresa de proyectar una clínica privada de cuidados paliativos problematiza la cuestión de los cuidados desde un punto de vista social, pues, de acuerdo con David Becerra Mayor (2015: 134), Susana y los viejos es una novela sobre la división del trabajo afectivo en la sociedad capitalista en la que los cuidados y los afectos han sido privatizados y convertidos en mercancía.

La mercantilización de los cuidados, es decir, el tratamiento de los cuidados y de la muerte como productos que se compran y venden, reproducen una lógica que conceptualiza a las personas y a los cuerpos desde su 
dimensión de cuerpos consumidores. La decisión de Felipe hijo y de Susana de llevar adelante el proyecto es el síntoma de un problema social más amplio que tiene que ver con la cuestión de cómo hacer frente colectivamente, desde el espacio común, a la cuestión de los cuidados. En otras palabras, la clínica privada de Susana y de Felipe responde a la ausencia de una responsabilidad colectiva al gestionar el bienestar y con respecto a los cuidados (Pérez Orozco, 2014: 70).

Aunque el título de la novela hace referencia a Susana, podemos pensar, con Becerra Mayor (2015: 134), que la protagonista de la novela es Clara. Clara es la trabajadora doméstica que comienza trabajando en casa de Felipe padre y de Micaela y que, una vez que Micaela muere y Felipe padre es trasladado a la clínica de cuidados paliativos de Susana y Felipe hijo, pasa a trabajar en casa de este último. Clara se presenta con una ascendencia de clase trabajadora:

La madre de Clara, con su niña cargada en la cadera, se mudó a un pequeño piso en alquiler y comenzó a fregar oficinas; a cuidar niños y viejos; a asistir por horas en casa de otras vecinas más afortunadas; a recorrer la ciudad de punta a punta en autobuses en los que casi siempre le tocaba ir de pie y se sofocaba; a comer barritas de chocolate porque el tiempo apremiaba y sus sobremesas transcurrían en un vagón de metro o en una camioneta, que transitaba por calles con la apariencia de estar techadas. No se podía respirar. La madre de Clara tiró del carro hasta que no pudo más y, con todo el dolor de su corazón, tuvo que pedirle ayuda a su hija: la petición significaba que Clara no podría seguir compatibilizando sus estudios con trabajitos esporádicos y que únicamente los trabajitos debían constituir su razón de ser (Sanz, 2006: 58).

La posición de Clara en la estructura y su sometimiento a un orden precario implica una serie de relaciones con las demás personas de su entorno de trabajo, que se sitúan siempre en un lugar superior a la hora de tratar con Clara. Desde el principio de la novela, se señala el atributo de invisibilidad que se asigna a las trabajadoras domésticas. De este modo, la invisibilidad epistemológica de las trabajadoras de cuidados y la ignorancia del impacto de este tipo de trabajo a lo largo de la historia se convierte en invisibilidad física cuando lleva a cabo su empleo:

Llevaba esas zapatillas con las que nadie la oía cuando caminaba por la casa. [...] Nadie sabía si estaba o no estaba. Clara poseía el privilegio fantasmagórico de la sorpresa y, sin embargo, hace unos días ella, desde dentro de su sigilo, había sido la sorprendida porque comprendió, de golpe, que ese estar o no estar, que la dotaba de fuerza y de cierta dosis de magia, podía también interpretarse como un ser o no ser (Sanz, 2006: 11)

El hecho de imponer un uniforme a Clara por mandato de Lorena se transforma en una primera frontera, "que establece, entre el cuerpo y ante los demás, el lugar que ocupa cada cual en un espacio autocontenido" (Precarias a la deriva, 2004: 31). El interés de Lorena por que lo lleve pasa por la intención de hacer aún más profunda la brecha que marca la diferencia de clase: "solo los que sirven llevan uniformes" (Sanz, 2006: 124). Esta brecha es la misma que hace a Max imaginar idilios románticos y vidas alternativas a las asistentas domésticas que conoce, convencido de alguien que desempeñe un trabajo como ese tiene que esconder un doble fondo en el que se esboce una vida de aventuras. Frente a las ficciones idealizadas de Max con Silvia Georghiou o la propia Clara, que ve en la cotidianidad de las asistentas una excusa para sus fantasías, se presentan las vidas de las mujeres inmigrantes con las que Clara se encuentra en el Cercanías y que se dedican a servir en otras casas:

Maximiliano ha escuchado durante horas los relatos de las vidas de las compañeras de Clara, que es de las pocas mujeres aborígenes que quedan en el oficio. [...] Clara repara en que, ante las historias reales de las asistentas que cogen los trenes de cercanías a las seis treinta y cinco de los amaneceres y lucen corroídos anillos de casada, que les comprimen los dedos rojos y asalchichados, Maximiliano Amaro no experimenta demasiado interés. A Maximiliano solo le llaman la atención las historias de las asistentas que terminan siendo hijas de los cónsules, licenciadas en ciencias políticas, aristócratas venidas a menos (Sanz, 2006: 229).

Se plantea de este modo la cuestión de las cadenas globales de cuidados, puesto que las mujeres se transfieren cuidados de unas a otras en función de diferentes ejes de discriminación. Esto implica, de acuerdo con Pérez Orozco (2014: 68), la emergencia de una ética reaccionaria del cuidado, en tanto que se normaliza la relación 
de las mujeres con el cuidado, así como una internacionalización de la división sexual del trabajo a través de la cual la crisis de los cuidados del centro y del norte se interrelaciona con la crisis de reproducción de los países del Sur global, que obliga a muchas mujeres a migrar y a dejar responsabilidades en sus lugares de origen que son asumidas por otros miembros de la familia.

Al final de la novela, y en virtud de las relaciones sexuales que Clara mantiene con Maximiliano, en las que se perciben las asimetrías de clase y la mala conciencia de Maximiliano que lo lleva a ejercer la caridad al acostarse con ella y tratar de redimirla, Clara queda embarazada de Maximiliano, el "patroncito". Sin embargo, toma la decisión de criar a su hija al margen de la familia Amaro y de Maximiliano, porque solo así podría conservar su posición de asalariada:

Clara se va a quedar en esta casa porque, como Fortunata, está embarazada y va a negarle al buen Maximiliano la posibilidad de que se ponga en su lugar y la entienda o le indique lo que debe hacer [...]. Maximiliano no sabe cuántas cosas le quedan por aprender de Clara Martínez, que llevará a su desenlace final la conspiración maligna de las asistentas y se quedará, con su panza, en la casa del padre, sin consentir que la conviertan ni en esposa, ni en barragana, ni en protegida. Se quedará con su tripa mientras friega los cacharros y le pagan su sueldo. (Sanz, 2006: 273).

Aceptar la protección de la familia y transigir a compartir la responsabilidad de los cuidados supondría para Clara la obligación de realizar gratuitamente, en virtud de su condición femenina, el mismo trabajo que hace a cambio de un salario contratada por Felipe padre. Clara sabe que si renuncia al trabajo asalariado se convertirá, como Micaela, en el paradigma de esposa abnegada y se verá obligada a una entrega completa a los cuidados sin obtener ninguna retribución a cambio. El salario y la posición de asalariada le otorgan a Clara cierta independencia económica, y la posibilidad, aunque remota debido a la precariedad del trabajo que desarrolla, de lograr cierta emancipación con respecto a los hombres, aunque no en relación con el capital, como señala Silvia Federici (en Requena Aguilar, 2014: s/p).

La decisión de Clara de subrayar el carácter del trabajo doméstico como una relación laboral pone contra las cuerdas la interpretación tradicional que establece que los cuidados representan una parte esencial de la condición femenina, un atributo natural de la personalidad de las mujeres. Considerarlo como un empleo supone poner el foco sobre el trabajo doméstico desde una perspectiva política (Federici 1975b: 36) y plantear que las consideradas "virtudes femeninas" poseen un valor económico calculable que ha sido invisibilizado a lo largo de los siglos. Esta postura entronca con las reivindicaciones del salario por el trabajo doméstico de los años 70, pues la demanda del salario por el trabajo doméstico

Es la demanda por la que termina nuestra naturaleza y comienza nuestra lucha porque el simple hecho de reclamar un salario para el trabajo doméstico significa rechazar ese trabajo como expresión de nuestra naturaleza y, a partir de ahí, rechazar precisamente el rol que el capital ha diseñado para nosotras (Federici, 1975b: 39).

Clara Martínez, desde la conciencia de clase que le permite reconocer nítidamente las relaciones de poder y de explotación que se inscriben sobre su cuerpo, entiende que la única manera de lograr una emancipación tiene que pasar por el reconocimiento del trabajo que mujeres como ella llevan siglos desempeñando. Al mismo tiempo, considerar el trabajo doméstico como trabajo conlleva politizarlo y poner sobre la mesa la explotación asumida en el seno de la familia, que se configura como la "institucionalización de nuestro trabajo no remunerado, de nuestra dependencia salarial de los hombres" (Federici, 1975a: 59). El acto de rechazar ser incluida como parte de la familia, la decisión de no participar de un corporativismo que lleve a estrechar lazos, a la identificación con quienes le extraen la plusvalía y que difumine las relaciones laborales de explotación es un acto político de resistencia por parte de Clara. Tras asistir a la invisibilización, al ninguneo y al énfasis en colocarla en una posición subalterna, Clara Martínez, que sabe que "su trabajo no la dignifica" (Sanz, 2006: 80), tiene muy clara su posición y quiénes son sus patrones: "Clara sabe que Max es tan solo un patroncito: un patrón subalterno, un patrón supeditado al patrón grande” (Sanz, 2006: 61). 


\section{Trabajo y eXPERIENCIA AUTOBIOGRÁfica: LA LECCIÓN DE ANATOMÍA}

Si en la anterior novela analizamos los mecanismos de representación de las trabajadoras a través de la ficción, en La lección de anatomía, por su carácter autobiográfico, es necesario partir de parámetros diferentes a la hora de llevar a cabo el análisis. Ahora el punto de partida lo constituyen las experiencias de Sanz como mujer y su capacidad de análisis como mujer concienciada de sus privilegios y de sus opresiones cotidianas. El lugar desde el que se mira resulta clave para entender el sentido de la novela: la autora hace memoria y reflexiona críticamente acerca de diversos episodios de su vida para plantear cómo su subjetividad ha sido construida colectivamente en interacción con otras personas. La necesidad de construir sujetos a través de experiencias colectivas tiene que ver con las relaciones entre los cuerpos a las que apunta Antonella Picchio:

Todo cuerpo está necesariamente en relación con otros cuerpos y, por lo tanto, mentes, en un contexto marcado por el espacio físico y los recuerdos basados en experiencias vitales, pensamientos y relaciones sociales [...]. Hombres y mujeres, en su propia y específica experiencia de vida, no pueden sobrevivir si no están envueltos en una red de relaciones sociales y utilizan cánones simbólicos y normas sociales que expresen el sentido y la estructura de esas relaciones. (2005: 20).

El trabajo cumple un papel fundamental a la hora de tejer esa red de relaciones sociales a la que hace referencia Picchio. En La lección de anatomia, el trabajo está problematizado: "quizá porque estamos hartos de jugar a trabajar y, sobre todo, de trabajar tomando conciencia que eres tú y no uno de tus otros yoes quien a menudo pierde el tiempo en beneficio de otros" (Sanz 2014a: 111). La contradicción capital-trabajo y la conciencia de ser explotada a través del trabajo asalariado se revelan claves en la construcción de la conciencia de la autora. La problematización se desarrolla también en torno al trabajo de cuidados, del que se destaca su dimensión afectiva. Enla novela, la narradora hace un repaso por los trabajos que ha desarrollado a lo largo de su vida y en ella no solo incluye los empleos, sino también aquellos trabajos no remunerados:

Suelo jugar a inventar historietas en las que estoy sometida a las tiranías de la moda [...], del trabajo y de la seducción, y me siento muy feliz. Al alcanzar la edad adulta y ocupar cualquier puesto de trabajo - he dado clase, he hecho publicidad, he consolado a gente que lloraba, he revisado los pagos con tarjeta de crédito a una empresa, he leído novelas por dinero, he escrito informes y folletos y materiales formativos, he preparado la comida y limpiado el váter de mi vivienda - no he podido desprenderme de la sensación de estar jugando, de que todo estaba bajo mi control y de que, en cuanto dejara de divertirme, me podría marchar (Sanz, 2014a: 108).

De esta manera, se consolida la intención de la autora de considerar el trabajo desde una perspectiva integral, es decir, desde un punto de vista que abarque no solamente el trabajo asalariado y, por tanto, socialmente considerado como tal, sino que incluya todos los trabajos necesarios para la reproducción de la vida social. La necesidad de los cuidados y el planteamiento de los seres humanos en sus facetas de vulnerabilidad e interdependencia como condiciones básicas de la existencia (Pérez Orozco 2014: 79) aparece en la novela de un modo explícito:

[...] yo necesitaba que mi madre fuera así. Que me regañase, que me quitase de en medio, que se hiciera obedecer. Necesitaba que mi madre curara las enfermedades con las manos, preparara la comida, me quitase las liendres del pelo cada vez que cogía piojos en el cine. Necesitaba que mi madre me dijera que no, que fuera un poco arisca, firme, nerviosa y resolutiva, que me castigara. Necesitaba que alguien me inyectase los benzetaziles para prevenir el reuma y lo soplos del corazón, que alguien solucionase los accidentes domésticos, supiera qué hacer cuando me subía la fiebre a cuarenta o cuando me descomponía quizá porque había comido demasiados tomates (Sanz, 2014a: 113).

Esta necesidad de un "otro" que, en este caso, es una "otra", plantea la cuestión de la maternidad, tema central en la novela en tanto que el rechazo de la narradora a convertirse en madre conlleva, desde las primeras páginas de la novela, una primera transgresión del código patriarcal hegemónico. De acuerdo con Vara Ferrero (2015), la narradora de La lección de anatomía va recorriendo las relaciones que establece con otros, pero, sobre todo, con otras, examinando y analizando lo que la ha convertido en lo que es y lo que ha tomado 
de todas esas relaciones que ha establecido con los demás para llegar a ser lo que es. El sujeto, por tanto, se construye por acumulación de elementos y de relaciones que mantiene con otros sujetos y a partir de ello, se plantea especialmente la relación con las mujeres de su entorno (su madre, su abuela Juanita, sus amigas de la infancia, de la adolescencia, sus compañeras de la universidad, sus compañeras de trabajo, etc.).

Al mismo tiempo, la necesidad de los cuidados y la vulnerabilidad de las personas pone de manifiesto que la maternidad y los cuidados son funciones laborales, en tanto que requieren de una serie de tareas que los sujetos tienen que realizar y que no es posible delegar en máquinas porque en ellas se establece una relación afectiva y emocional. La maternidad se plantea como un espacio problemático en el que la narradora puede decidir libremente no entrar, si bien a lo largo de la autobiografía novelada hay una voluntad de señalar la presión social a la que se somete a las mujeres para desempeñar tal papel, tales como los comentarios de la madre de la narradora expresando su anhelo de ser abuela - "Ahora, a veces protesta porque no le he dado nietos" (2014a: 30) - o los vestidos que había confeccionado la abuela Juanita para los hijos de Marta -"Mi abuela Juanita, antes de morirse y de que las manos se le deformaran a consecuencia de la artrosis, dejó confeccionados dos jerseicitos para esos bebés que yo no pariré nunca” (Sanz, 2014a: 37).

La función laboral de la maternidad se expresa, de este modo, a través de los trabajos que se realizan y a partir de la dificultad de diferenciar con nitidez el fin de la jornada laboral de la madre de la narradora. La doble jornada laboral a la que se enfrenta le provoca la necesidad de delegar en terceras personas buena parte del trabajo doméstico y de cuidados, de acuerdo con lo que se entiende como cadenas de los cuidados. Mientras ella acude a su puesto de trabajo remunerado, necesita que alguien cuide a su hija Marta. Esta responsabilidad recae en la abuela Juanita:

Mientras mi madre está tratando a Corina, a algún paralítico cerebral o a alguna señora con periartritis que en sus buenos tiempos habría jugado al tenis — la clínica en la que trabaja mi madre es privada y cara —, me cuida mi abuela Juanita, que era la madre de mi padre (Sanz, 2014a: 38).

El cuidado de Marta no es la única tarea de cuidados que se encarga a terceras personas, sino que, en esta misma lógica de delegar tareas, el trabajo de limpieza de la casa recae en Antonia, empleada doméstica que procede de una familia humilde de Jaén. De este modo, se problematiza la cuestión de la posición y el lugar desde el cual miramos a los demás, en tanto que a la narradora - "yo siempre he sido una señorita pequeñoburguesa y no siento culpa” (Sanz, 2014a: 133)-, desde su lugar privilegiado, le resulta repulsiva la figura de Antonia: "Le escatimaba los besos, porque Antonia olía a sustancias ácidas y era muy cariñosa [...] Yo no le decía a Antonia la verdad, pero con una cortesía más que dudosa la empujaba cuando trataba de estrujarme entre los morcones de sus brazos" (Sanz, 2014a: 135).

La cuestión de las relaciones que se establecen entre los cuerpos lleva aparejada la idea de la política de la posición: en la interacción con otros que ocupan lugares diferentes en la estructura, se producen relaciones de poder y de subordinación y se hacen visibles los privilegios de etnia, clase o género. En el caso de La lección de anatomía, esto nos lleva a analizar dónde se situaba la pequeña Marta con respecto a la trabajadora doméstica, dónde se sitúa la Marta adulta y qué ha pasado para ese cambio, así como la situación de la narradora con respecto a la actitud de la niña. Así, desde una posición de privilegio de clase, la narradora rememora sus opiniones con respecto a Antonia:

Sólo sobraba. Y me molestaba no tanto por ser una víctima -y es un hecho comprobado que las víctimas molestan-, como por el hecho de que hablase mal y de que su trabajo fuera el de limpiar la mierda de los otros [...] Antonia me hacía daño en los oídos en una época en la que yo admiraba a las empleadas de las agencias de viajes y a las secretarias bilingües (Sanz, 2014a: 136).

El filtro de la autocrítica y del análisis de las relaciones laborales de clase y de género que ha observado a lo largo de su vida provocan en la narradora la adquisición de una conciencia de clase y de género que se revela de manera explícita en las páginas de la autobiografía cuando se llevan a cabo reflexiones sobre la lucha de 
clases: "La lucha de clases es inclemente -tiene que ver con la invisibilidad y con los estratos geológicos, con la tierra que somos capaces de echar por encima de lo que no queremos ver" (Sanz. 2014a: 138).

La narradora adulta se desmarca de su opinión de la etapa infantil, teñida de clasismo y de desprecio hacia las trabajadoras domésticas, pero lo hace a través de un ejercicio de autocrítica y de la honestidad de reconocer sus actitudes clasistas de la infancia y la importancia del lugar desde el que se habla y, con ello, de la necesidad de los escritores de evitar caer en paternalismos al llevar a cabo cualquier representación de la realidad a través de la literatura o del arte:

\begin{abstract}
Antonia fue la primera señora de la limpieza que pasó por mi vida. Hasta hoy he conocido a algunas más y solo puedo afirmar que no todos los trabajos dignifican —de hecho, no dignifica casi ninguno. De las señoras de la limpieza he aprendido, como persona dedicada a la escritura, que es muy complicado hablar de los pobres, porque de la misma forma que resulta inverosímil que tomen la palabra, si alguien la toma por ellos, el discurso se desliza por la pendiente de la sensiblería o de la condescendencia. Hoy estoy muy arrepentida de que Antonia me oliera a sustancias ácidas, pero prefiero confesarlo que hacerme la buenita (Sanz, 2014a: 139).
\end{abstract}

Amaia Pérez Orozco, en relación con la noción de "conocimientos situados" formulada por Donna Haraway (1988), plantea partir de la parcialidad como modo de acceso a la objetividad. Se redefine, de esta forma, la objetividad apelando a la localización de los cuerpos desde un punto de vista relacional para definir la posición que ocupan en la estructura social jerárquica y observar cómo se construye la mirada desde diferentes posiciones, de tal modo que seamos capaces de "explicitar la posición que habito/habitamos (colectivamente) en esta jerárquica estructura social y hacerme/hacernos cargo de lo que miramos desde ahí, de cómo lo miramos y para qué" (Pérez Orozco, 2014: 72).

La vinculación que existe entre el cuerpo y el trabajo se pone de manifiesto al señalar la relación entre las tiranías de la moda, del trabajo y de la seducción, puesto que se plantea la entrega total al ámbito laboral desde la modificación de los hábitos asociados al cuerpo. En este sentido, en otro momento de la autobiografía, cuando se hace referencia al primer trabajo de la narradora como profesora de español para altos ejecutivos extranjeros, se plantea la necesidad de vestirse de manera diferente a como se viste en su cotidianidad: "Cada tarde, me visto cuidadosamente para enseñarle español a Jonathan y, a menudo, no me reconozco delante del espejo. Me calzo zapatitos de tacón y me pongo chaquetas ajustadas a la cintura sin saber a quién quiero gustar" (Sanz, 2014a: 284). La autodeterminación corporal queda subyugada al trabajo, tal y como ha puesto de manifiesto el colectivo madrileño de investigación militante Precarias a la deriva:

La fusión, en el cuerpo, de vida y trabajo es un hecho normal para muchas mujeres que trabajan de cara al público, por ejemplo en el comercio, la hostelería y el nuevo trabajo administrativo, en el que se entremezclan papeleo telemático y atención al cliente. El deseo de gustar (a una misma y a las demás), un deseo poderosamente domesticado en las mujeres, es aquí recuperado para el control laboral difuso y la producción de una subjetividad basada en la entrega sin condiciones (Precarias a la deriva, 2004: 33).

Con todo, La lección de anatomia plantea como problemáticas las intersecciones entre trabajo, cuerpo y lenguaje al considerar la posición desde la que se habla como punto de partida para articular las miradas a la realidad. La interdependencia de las personas queda manifestada en la construcción de la identidad del sujetonarradora a través de las relaciones que establece con las y los demás sujetos de su entorno, lo que desmonta los presupuestos de la ideología neoliberal que establecen la posibilidad de construcción de un sujeto fuerte e individualizado sin lazos solidarios con su entorno ni relaciones de dependencia mutua.

\title{
Conclusiones
}

La relación entre la realidad y sus representaciones es un tema recurrente en la narrativa de Sanz. La autora concibe la cultura como medio por el que se reproduce la ideología dominante, pero también como espacio a través del cual se producen discursos ideológicos. Es en este punto en el que se plantea la dimensión 
transformadora de la literatura, en tanto que se considera la posibilidad de articular contrarrelatos. Sanz, a través de su obra narrativa, ensaya una problematización de la realidad desde un punto de vista interseccional que tiene en cuenta los criterios de género y de clase para la construcción social de la realidad.

Esta perspectiva acerca de las representaciones de la realidad provoca una reflexión sobre las diferencias de clase en las representaciones del cuerpo femenino en el caso de Susana y los viejos, así como en la representación autorreflexiva del propio cuerpo en La lección de anatomía. Tal reflexión sobre el cuerpo lleva aparejada la cuestión de los cuerpos productivos y, con ella, la problematización del trabajo, especialmente el trabajo realizado por las mujeres en sus múltiples facetas y tipologías desde su importancia para el sostenimiento de la vida humana. A través de dicha problematización, su obra entronca con la novela social y pone sobre la mesa temas relacionados con las cuestiones clásicas que ha tratado la novela social, esto es, la lucha de clases, la explotación, la discriminación y las jerarquías sociales en función de diferentes ejes de dominación cuya existencia la autora considera necesario poner de manifiesto.

\section{BibLiografía}

Becerra Mayor, D. (2015). Marta Sanz, del realismo a la posmodernidad. En D. Becerra Mayor (Coord.), Convocando al fantasma. Novela critica en la España actual (107-161). Madrid: Tierradenadie Ediciones.

Bonatto, A. V. (2017). Representaciones de identidades femeninas a partir de tradiciones masculinistas en Susana y los viejos de Marta Sanz. La Colmena, 94, 9-23.

Carrasco Bengoa, C. (1991). El trabajo doméstico: un análisis económico. Madrid: Ministerio de Trabajo y Seguridad Social - Col. Tesis Doctorales.

Castillo, J. J., Caravantes Vidriales, R., García Aristegui, D., González García, C. y Lleó Fernández, R. (2013). Qué hacemos con el trabajo. Madrid: Akal.

Federici, S. (1975a). Contraatacando desde la cocina. En Revolución en punto cero. Trabajo doméstico, reproducción y luchas feministas (51-66). Madrid: Traficantes de Sueños.

Federici, S. (1975b). Salarios contra el trabajo doméstico. Revolución en punto cero. Trabajo doméstico, reproducción y luchas feministas (35-45). Madrid: Traficantes de Sueños.

Federici, S. (2013). Introducción. Revolución en punto cero. Trabajo doméstico, reproducción y luchas feministas (21-34). Madrid: Traficantes de Sueños..

González, S., Larraz, F. y Somolinos, C. (2014). Intersecciones entre relatos: literatura y discurso dominante. Entrevista a Marta Sanz. Contrapunto. Publicación de Crítica e Información Literaria, 10, $24-27$.

Haraway, D. (1988). Situated knowledges: the science question in feminism and the privilege of partial perspective. Feminist Studies, 14(3), 575-599.

Hermandad Obrera de Acción Católica- HOAC. (2013). Entrevista a Isaac Rosa, autor de La mano invisible. Recuperado de: . Última consulta: 20/02/2017.

Laboratorio Feminista (2006). Transformaciones del trabajo desde una perspectiva feminista, Madrid: Tierradenadie ediciones.

Martín-Cabrera, L. (2010). Contra la suspensión de la Mirada crítica: reflexiones sobre la persistencia del conflicto capital/trabajo en la cultura contemporánea española. Arizona Journal of Hispanic Cultural Studies, 14, 117-138.

Nash, M. (1993). Identidad cultural de género, discurso de la domesticidad y la definición del trabajo en las mujeres en la España del siglo XIX. En G. Duby y M. Perrot (Ed.), Historia de las mujeres, vol. 4, El siglo XIX (612-623). Madrid: Santillana.

Pérez Orozco, A. (2014). Subversión feminista de la economia. Aportes para un debate sobre el conflicto capital-vida. Madrid: Traficantes de Sueños.

Picchio, A. (2005). La economía política y la investigación sobre las condiciones de vida. En G. Cairó i Céspedes, M. Mayordomo Rico (Comps.), Por una economia sobre la vida. Aportaciones desde un enfoque feminista (17-34). Barcelona: Icaria. 
Precarias a la deriva. (2004). A la deriva por los circuitos de la precariedad femenina. Madrid: Traficantes de Sueños.

Requena Aguilar, A. (2014). 'Es un engaño que el trabajo asalariado sea la clave para liberar a las mujeres'. Entrevista a Silvia Federici. Eldiario.es, 24/05/2014. Recuperado de: http://www.eldiario.es/economia/engano-trabajo-asal ariado-liberar-mujeres_0_262823964.html. Última consulta: 25/02/2017.

Rich, A., (1984). Apuntes para una política de la posición. En Sangre, pan y poesía. Prosa escogida 1979-1985. Barcelona: Icaria.

Sánchez Dueñas, B. (2012). Relecturas y creación desde la subversión: Susana y los viejos, de Marta Sanz. Signa, 21, 625-649.

Sanz, M. (2006). Susana y los viejos. Madrid: Destino.

Sanz, M. (2007). La novela española hacia el nuevo milenio: algunas impresiones. Cuenca: Centro de Profesores de Cuenca.

Sanz, M. (2010). Perra mentirosa / Hardcore. Madrid: Bartleby.

Sanz, M. (2014a). La lección de anatomía. Barcelona: Anagrama.

Sanz, M. (2014b). Nombrar el cuerpo, conquistar el territorio. Cuadernos hispanoamericanos, 772, 58-73.

Vara Ferrero, N. (2015). Lecciones del 'yo': autobiografía, ficción y sujeto ético en Marta Sanz. RECIAL: Revista del Centro de Investigaciones de la Facultad de Filosofia y Humanidades, Áreas Letras, 6(7).

\section{Notas}

1 Este artículo se inscribe en la investigación desarrollada en el marco de la ayuda de Formación del Profesorado Universitario concedida por la Universidad de Alcalá (FPU-UAH). 